\title{
A Parkinson's Disease Journey from Patient side view
}

\author{
Jorge Garza-Ulloa*1 and Gordon Johns ${ }^{2}$ \\ Research Consulting Services garzaulloa.org, University of Texas El Paso, USA
}

*Corresponding author: Jorge Garza-Ulloa, Research Consulting Services garzaulloa.org, University of Texas El Paso, USA. jgarzaulloa@ miners.utep.edu, jorge@garzaulloa.org

To Cite This Article: Jorge Garza-Ulloa. A Parkinson's Disease Journey from Patient side view. Am J Biomed Sci \& Res. 2019 - 5(1). AJBSR. MS.ID.000868. DOI: 10.34297/AJBSR.2019.05.000868

Received: 眥 August 24, 2019; Published: 眥 September 03, 2019

\begin{abstract}
There are a lot of research papers about Parkinson's disease from the medical point of view, this research paper is from the heart's patient side view, there are aspects of Parkinson's that only those living with it truly understand. This paper is based on a treasure from a personal experience into a Parkinson's disease journey of Gordon Johns. Each degenerative neurological disease patient are real heroes, that fight every day with the evolution of their symptoms that struggle their life 24/7. We, as Biomedical researchers on degenerative neurological disease believe that observing the evolution from the symptoms and emotions progressions, and how they are handling by patients will help: researchers, doctors, others patients, caregivers and all people with human kindness to understand this terrible progressive disease that still doesn't have cure. Testimonies like this, will point a more human way to find and develop new treatments that will help to deal with the disease for a better quality of life of Parkinson's patients and find a way to slow down or stop the disease progression or find a cure in the near future for it. I add my sections for: analysis of this case from a Biomedical researcher perspective, Parkinson's disease general acknowledges and conclusions to find ways to deal with this cruel disease.
\end{abstract}

Keywords: Parkinson's Disease; Tremors, Movement Disorders; Postural Instability; Parkinsonism; Idiopathic Parkinson's; Atypical Parkinsonism; Multiple System Atrophy

\section{My Journey into an Obscure Neurological Disorder}

\section{by Gordon Johns*}

"I have no technical background in these diseases - no clinical training of any kind - but I've been told that detailed accounts of patient experiences can be helpful to the professionals in their study of these terrible diseases. I hope something about my case will be helpful to them"

Gordon Johns died on April 26, 2019.

Special thanks to Helena Keeley for send me this testimony treasure.

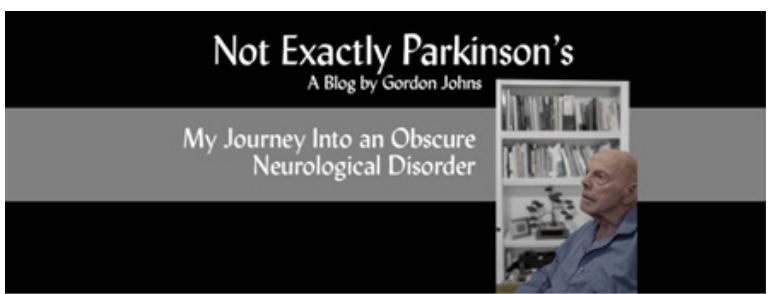

Figure 1.

\section{Introduction (By: Gordons Johns, February} 20,2019]

My name is Gordon Johns. I am 83 years old and retired. I've been happily married to my wife, Carole, for 19 yrs. In February of
2013, I consulted a neurologist because of slowly increasing body weakness, nocturnal leg cramps, and episodes of forgetfulness. After performing a few tests, he gave me a diagnosis of Parkinson's Disease. That diagnosis came into question with my second neurologist, when my symptoms, which had not matched any of the classic symptoms of Parkinson's Disease to begin with, diverged even further from those classic symptoms. From then until now (2019), I consulted three more neurologists. They performed many tests and tried many medicines, but none of them led to a solid diagnosis.

Last October, my current neurologist concluded that I have "Multiple System Atrophy," or MSA. There are two kinds of that disease; both are terminal. My kind is "MSA of the Parkinson's type," or "MSA-P" for short.

I would have preferred a disease that had fewer words in its name. .. and one that wasn't terminal. Some of my symptoms have been very unusual over these years, especially the ones that got better and get worse independently of my medicine.

I've always been interested in the subtleties of my own thoughts and feelings, and I wanted to share the strange experiences I was having. At first, I planned to write the blog only for our friends and relatives, but after giving a few sample pages to therapists, 
technicians, and doctors, I became persuaded to make my blog known to professionals as well.

I have no technical background in these diseases - no clinical training of any kind - but I've been told that detailed accounts of patient experiences can be helpful to the professionals in their study of these terrible diseases. I hope something about my case will be helpful to them. If you find something in this blog that seems useful to you in a clinical sense, make sure that it is consistent with current scientific knowledge.

\section{Thirty Seconds of Dementia}

One afternoon in August 2017, I was home alone, thinking about something or other, and at some point, I wanted to know the numerical difference between eight and five. I don't remember now why I needed that-maybe it was eight o'clock then and I was checking to see how many hours had passed since I took some medicine at five o'clock. It stunned me that the difference between eight and five wasn't immediately obvious! How could I not know it? I was frightened. I'd had episodes of memory loss that my neurologist said were attributable partly to my disease and partly to the normal aging processes in an 82-year old brain-but nothing had been as extreme as this!

I was determined to get the answer to this trivial problem. I closed my eyes and closed my hand to make a fist. I counted up from five to eight, extending one finger for each advance. I thought I had made three counts, but, oddly, I wasn't sure. I looked down at my hand. Yes, three fingers-so the answer to my problem was three!

But now, what was the problem? My memory of it had vanished! All I could recall was that I had two single-digit numbers to start with, and I needed to subtract one from the other to get the answer to... some question I had wanted the answer to.

Now, what were those two numbers again? I had forgotten them too. In just seconds!

I realized that this succession of memory failures was very bizarre, and I thought it would be important to recall it later if I could. In passing, I noted that I was reasoning very well, but my memory was faulty. I decided to review, mentally, all I could recall happening, and I did that several times, in hope of burning it into my enfeebled memory.

While doing that, I suddenly remembered the numbers eight and five! Good! I found a piece of paper and wrote a note to my future self:

\section{$8-5=3$ what is this about?}

I found that piece of paper later, and it helped me remember enough to tell you the little story above-a tale about the time my malfunctioning brain solved a forgotten problem to produce a useless answer.
Notes:

I don't exactly have "dementia" and I don't exactly have "Parkinson's Disease" either-although the latter was my initial diagnosis five years ago. My episodes of extreme forgetfulness and confusion were exactly that: episodes. After each one, my mind returned to its previous state. The word dementia refers to a condition that is constantly worsening. Dementia doesn't go off and on.

There is another factor, however. Brain images over the years have shown increasing vascular disease consistent with my age. Whatever the contribution of this to my behavior, it is constant, not intermittent.

Regarding the title of this post, "Thirty Seconds of Dementia," thirty seconds is just a wild guess. I can't know how long that episode really lasted, because other thoughts could have occupied my consciousness, and then never called to mind after that.

\section{Learning to Walk in a New Way}

Four years ago, a year after I'd been diagnosed with Parkinson's, something strange happened with my legs—-something I'd never experienced before.

I was standing by the table in our kitchen nook, looking down at my array of medicines. I turned to walk to my recliner in the family room, about 15 steps away. But something went wrong. I stopped walking. I don't mean I decided to stop walking; rather I found myself standing still.

It was weird and definitely scary. What could have stopped me? I glanced down at my legs and feet. I had felt no resistance. What the hell is going on?

Quickly then, I stumbled the rest of the way to the recliner and flopped into it. I took a deep breath and tried to relax, but my mind was racing. Oh, God! Am I having a stroke? Am I getting some kind of paralysis in my legs?

Then it occurred to me: This might be a new symptom of my Parkinson's. I'd never had any bradykinesia (resistance to body movements, also called "stiffness") but I needed to check it out. I was able to lift each leg up off the chair easily, so my hip joints were fine. With each one I also flexed all the other joints-knees, ankles, toes. No stiffness, no discomfort of any kind. Stiffness is one of the cardinal symptoms of Parkinson's disease, but here: all good!

I wanted to talk to Carole, my wife, but she was away on an errand. I could call her, but I decided to wait. No need to frighten her now. I had to try walking again. Gathering my courage, I stood up, intending to retrace my path from the chair back to the nook table. I took slow steps. Along the way I heard birds chirping. Carole had a clock in her office that makes bird sounds. . . and then I stumbled! 
I had been watching my feet while I was walking, but when the chirping sounds distracted my thoughts, my walking stopped. Apparently, I had to pay continuous attention to my walking in order to keep it going...whereas it had been automatic all my life. I turned around and made my way back to the recliner, watching my feet all the way.

After I calmed down, I reflected on the whole walking thing. I thought about how, when we were children learning to walk, we first had to learn to take a single step, probably while mommy's hand held us up. After that, to execute one step after the other, we had to think about every step we took. Our conscious intention caused special signals to be sent to our brain, which would then direct our muscles to lift one leg and move it forward, and then put that leg down again. We had to will every step we took.

I'm no expert in this area, but I was willing to make a few suppositions. As we pre-toddlers practiced doing this, our brain was building a set of detailed "motor commands" (muscle commands) to direct the muscles of one leg to execute one step. As we moved along, holding onto a couch or table, our brain refined its motor commands to make taking a step easier and faster. As we got more practice in single-stepping, that set of commands in our child's brain finally combined to make an automatic system that enabled us to walk without conscious effort, except for the simple intention to begin walking. Perhaps because of my Parkinson's, the automatic walking commands that my brain developed when I was little, are damaged.

Now as adults our automatic walking system probably follows these steps: take a step with one foot, take a step with the other foot, and then repeat. It's like those shampoo instructions, "Lather, Rinse, Repeat," except that in my motor commands, the repeat step was missing or damaged. My brain will execute each forward step, but I had to trigger each "repeat" myself.

Days went by, and I discovered that I didn't have to watch my feet with each step, but I had at least to think about each step. It's like thinking, "left... right... left... right..." but you don't have to think the actual words.

I had read nothing about this kind of experience in my Parkinson's disease books. I thought that maybe all PD patients with walking problems had a similar transitional experience. Later similar limitations occurred with my hand movements and fine motor movement of the fingers. I was sure that for the rest of my life I would need to "monitor" these everyday motions this way.

It's not as burdensome as it may sound. Suppose that you and I are walking along, chatting about something that requires some light concentration. If my walking required, say, $10 \%$ of my conscious attention (I have no idea what the real number would be), then I would still have $90 \%$ of my attention to devote to our discussion. That's not a major loss. I don't think either you or I would notice it affecting my thoughts or remarks.

Afterwards, walking took less and less attention as the weeks slipped by. Now it's mostly liked the old normal. Occasionally I have to pay attention, but I notice this only a few times a day. I must attend to some arm and hand movements too. Overall, the whole thing turned out to be inconsequential. And, of course, I wasn't frightened of it anymore.

\section{Standing Still Without Falling}

Many months after I found that I couldn't walk right, I acquired another disability-I couldn't stand right either.

When we stand still, and if our hands or body aren't in contact with something secure, our body will occasionally tip slightly, at random, forward or backward from the vertical. This is natural. Our brain detects the problem and flexes our feet at the ankles as needed to bring us upright. Normally we're not aware of this process. It happens unconsciously.

I am going to take a break here to describe something interesting. If you already know what "proprioception" is, you can skip the next couple of paragraphs. If you would close your eyes right now, you would still know the spatial configuration of your body. For example, you'd know where your arms and legs are. How would you know? You might think it's because you remember the last place you put them. But this isn't how you know-you know because you have a sense of "proprioception."

All moving parts of your body send signals to the brain with information about their position and their motion. These signals, augmented by equilibrium information from your ears, enable your brain to maintain a "proprioceptive model" of your body. In the case where your body is standing but starting to tilt away from the vertical, your brain's proprioceptive model detects that. When this is detected in the model, your brain activates a motor control sequence (I'm guessing about that term) and sends the appropriate motor control signals to your legs and feet to bring you upright.

As we stand, we're not aware that our body tips forward and backward a little bit at various times, and the problem is corrected automatically.

It's a great feature.

But it no longer works for me.

The change came many months after I found I could no longer walk without attending to each step. Standing at my bathroom basin, I suddenly felt myself falling backward. A quick backward step stopped my fall. We are all familiar with that when it happens because of a sudden gust of wind or a slight contact with someone in a crowd. But I was worried about a serious fall. 
I went to the kitchen floor for good contact, barefoot, and gripped a counter for stability, and experimented. Sitting for a while, standing again, standing while reading a book aloud, standing while thinking about this file, or trying to think of nothing. It was all the same. The slight imbalance of my body when it occurred was either using a broken motor control sequence or not using any at all. My balance mechanisms in my brain and ears tell me inform me that I'm tipping, so I correct that by pressing toes down or pressing heels down.

And from that day until now, this has been the only way I can stand without support. It's not a serious drain on energy but the repeated interruptions of my conscious thought process are annoying.

For long-term activities like brushing teeth or shaving I find it helpful to lean forward with my stomach against the edge of the counter. This contact holds me up without any action at the ankles, but then I get a pain in my lower back. Why? Because those muscles are the ones holding my body in the slightly bent position needed to stay in contact with the counter.

\section{My Hand Forgets How to Brush My Teeth}

One morning I discovered that I couldn't brush my teeth. I had put a blob of toothpaste on the brush and put the brush in my mouth. And nothing happened!

I wanted to begin brushing but it just wasn't happening. I felt surprise and fear. There was another feeling that was uncomfortable, but I didn't identify it until days later: it was a sense of helplessness.

So, I was standing at the bathroom mirror looking at myself holding the brush that was against my teeth but not brushing any teeth. I reasoned-guess what? - that the motor control sequence in my brain for brushing teeth was no longer functioning. My conscious mind had transmitted the order to "do the tooth-brushing thing" to my brain, but the appropriate series of motor commands to my arm and hand were not being transmitted-as they had been all my life. Those motor command sequences had been damaged or eliminated by my disease.

I did finish brushing my teeth, but I had to think about (again, to will) each separate movement of the brush. I noticed that the standard back-and-forth wiggle was just one thing I had to do. I also had to decide when to stop and transfer the brush to the inside of the teeth, and switch between left, center, and right, to ensure that I had brushed every surface. Plus, pushing the bristles against my teeth was a lot of work, per my all-body weakness.

Since that day I've been consciously responsible for every brushing motion of my toothbrush. I hoped my brain might relearn and create a new motor control sequence from all the repetitions. I think this is what happens when a veteran with brain damage, or a stroke victim, is able to relearn to walk. But it didn't work with my tooth brushing.
I suspected that my disease might not enable this relearning because I had seen a similar failure before, in the kitchen. One day I found that Carole had rearranged the flatware in the kitchen drawer. The knives, forks, and all the rest had been in the same compartments, with each tool oriented the left-or-right, up-ordown same way for many years. On that day I realized that I was in the habit of yanking the door open and seizing the tool I wanted, by the handle, without looking.

Now I had to look down and govern my hand in the "seizing," just as I had had to govern each step in my new way of walking. Carole offered to put the flatware back to its former arrangement for me, but I wanted to see if my brain would create some new motor controls. And it did, or something equivalent, because now I pretty much know where my hand is going when I reach for a utensil. My eyes don't have to track my hand. I recovered from that particular "disability."

But the brushing of my teeth remained as effortful as it was the very first time I did it myself. I wasn't going to relearn that.

So, I bought an electric toothbrush.

\section{Not Yet Parkinson's (by: Gordon Johns Last blog story)}

This short post goes way back to the summer of 2002. I consulted a neurologist with complaints of body weakness, leg cramps, and occasional forgetfulness and confusion. He ordered lab tests, and a brain MRI, and a nerve conduction study. He said that those were normal for a man 67 years old. Neuropsychological tests showed a slight memory impairment.

The reason I am telling you this is what the doctor said just as I was going out the door:

"Gordon, there's nothing in your test results or in your symptoms that give even the least suggestion of Parkinson's Disease. Nothing at all."

I looked at him in puzzlement.

"Nevertheless, there's something that I sense about you-as though it were a smell, but it's not actually a smell". He smiled briefly. "I think you're going to be coming back to us in ten years with Parkinson's Disease. Now I see the grin of pride.

I don't remember any further discussion but driving home I was angry. This doctor had predicted something potentially devastating for my future health with no clinical evidence for it! And it was a disease that no one can prevent or prepare for!

How could this neurologist not know that a comment like this might infect the patient's attitude or feelings toward his or her future death for a long time-say the next ten years? How many thousands of times might he or she have little twinges of fear when contemplating their future demise?

What if the patient had thought, mistakenly, that Parkinson's disease is terminal? Or if the patient misremembered and thought 
the neurologist had said Huntington's Disease, which is terminal? What if the patient was suffering from depression, and this remembered "bad news" contributed to a suicide?

Doctors know they have the power to hurt patients accidentally with their words, but the careless use of this power, to my mind, is unconscionable.

During that span of ten years, I didn't have much reaction to what that neurologist said that day, but it irked me profoundly ten years later when I realized that this careless SOB had been right about me! I was pleased to learn that he was no longer practicing in my area.

"If you find something in this blog that seems useful to you in a clinical sense, make sure that it is consistent with current scientific knowledge".

Gordon Johns

\section{About the Author: Gordon Johns}

\section{Education:}

BS Physics, Florida State University, 1957.

Graduate studies, Advanced Nuclear Physics and Reactor design, 1957-58, Rensselaer

Polytechnic Institute.

\section{Employment:}

Associate Reactor Physics Designer, Knolls Atomic Power Laboratory, Schenectady, NY.

Aerospace Engineer, Leader, Scientific Software Group Honeywell Aerospace, Orlando, FL.
Senior Software Engineer, Space Station Program, Link Flight Simulation, Houston, TX.

Member of the Technical Staff, Artificial Intelligence \& Robotics Section, Space Data Systems Department, MITRE Corporation, Johnson Space Center, Houston, TX.

\section{Publications and Honors:}

"The FICS System," United States Atomic Energy Commission, Naval Reactor Physics Handbook, Volume One, 1964.

"Dynamic Display of Electronic Crew Procedures for Space Station," The Journal of Spacecraft and Rockets, Jan. 1989.

"The Steps Methodology," Award of Excellence, state-wide winner, FL Technical Communication Competition, 1996.

National Physics Honor Society.

Co-Inventor, U. S. Patent 4,033,336, System for Sensing and Recording Medical Information, July 5, 1977.

Former member: Mensa, Intertel, Triple Nine Society.

Invited Speaker, American Institute of Aeronautics and Astronautics, Reno NV, 1988.

\section{Analysis from a Biomedical Researcher Perspective (by Jorge Garza-Ulloa)}

In every real story there are many opinions from different points of views, the real challenge for a degenerative neurological researches and professionals in this field is to: listen, collect and analyze the real facts to learn from them and increase the probability to find appropriate solution that will help in the life affected by this terrible degenerative neurology disease.

\begin{tabular}{|c|c|}
\hline $\begin{array}{l}\text { Analysis from a Biomedical } \\
\text { researcher perspective (by Jorge } \\
\text { Garza-Ulloa) }\end{array}$ & Introduction \\
\hline Patient side view & $\begin{array}{l}\text { The patient for } 16 \text { years (from 2013) consulted four different neurologists. He received many different } \\
\text { diagnostics based on his symptoms were not the classic one, and he was very confused if he has Parkinson' } \\
\text { disease or not until he received the final diagnose on 2019, that he had: Multiple System Atrophy }\end{array}$ \\
\hline Research side view & $\begin{array}{l}\text { Parkinson's disease is a progressive neurodegenerative disease that produce neuronal cell death in the brain, } \\
\text { altering the central nervous system, and affecting the regulation of the human movements and emotions that } \\
\text { are deteriorating gradually. Parkinson's disease is a highly variable disease, meaning that different patients } \\
\text { have different combinations of symptoms, and those symptoms can be at varying severity levels. The main } \\
\text { problem for diagnosis and treatment of this disease there are not specific tests exists to diagnose Parkinson's } \\
\text { disease. Only your doctor trained in nervous system conditions (neurologist) will diagnose Parkinson's disease } \\
\text { based on your complete medical history, a review of your signs and symptoms, and a neurological and physical } \\
\text { examination [4] }\end{array}$ \\
\hline Ideal Goal & $\begin{array}{l}\text { There is a need to develop a way to detects Parkinson's diseases on early stages with specific tests and } \\
\text { symptoms. }\end{array}$ \\
\hline Current advances & $\begin{array}{l}\text { Some of them are: Variations in the genetic combination of certain genes elevate the risk of PD. Studies } \\
\text { have reported that mutation in the LRRK2 (leucine-rich repeat kinase 2), PARK7 (Parkinsonism Associated } \\
\text { Deglycase), PRKN (Parkin RBR E3 Ubiquitin Protein Ligase), PINK1 (PTEN-induced putative kinase 1) [5] or } \\
\text { SNCA (alpha-synuclein) contribute to the risk of PD[6]. These DNA test are on evaluation as test from early } \\
\text { signs [1]. }\end{array}$ \\
\hline
\end{tabular}

\begin{tabular}{|c|c|}
\hline Section: & Thirty Seconds of Dementia \\
\hline $\begin{array}{c}\text { Patient side } \\
\text { view }\end{array}$ & The patient detect himself problems with his reasoning and his memory and deduct that the dementia refers to a condition that is \\
constantly worsening.
\end{tabular}




\begin{tabular}{|c|c|}
\hline $\begin{array}{l}\text { Research side } \\
\text { view }\end{array}$ & $\begin{array}{l}\text { Give more information to Parkinson's disease patients and caregivers to understand the difference between dementia and cognitive } \\
\text { problems including memory difficulties, slowed thinking, confusion [1]. Cognition is a general term that refers to the mental abilities } \\
\text { that we use to process information and apply knowledge. These mental processes allow us to perform daily functions such as paying } \\
\text { attention, solving problems, and remembering where items are and how to do certain tasks. }\end{array}$ \\
\hline Ideal Goal & $\begin{array}{l}\text { There is a need to develop cognitive tests to evaluate and measure the state of the mind on Parkinson's disease patients, and track if } \\
\text { the cognitive is declining and in what proportion. }\end{array}$ \\
\hline $\begin{array}{c}\text { Current } \\
\text { advances }\end{array}$ & $\begin{array}{l}\text { Many Artificial Intelligence and Cognitive science algorithms and methods are being develop for help in the solution of this problem } \\
\text { [7]. }\end{array}$ \\
\hline Section: & Learning to Walk in a New Way \\
\hline $\begin{array}{l}\text { Patient side } \\
\text { view }\end{array}$ & $\begin{array}{l}\text { He detects that something strange happened with his legs and have problems with his walking feeling like a of paralysis in his legs. He } \\
\text { develops his own technique to rewire the neurons of his brain on how to give the orders to his leg to move. }\end{array}$ \\
\hline $\begin{array}{l}\text { Research side } \\
\text { view }\end{array}$ & $\begin{array}{l}\text { Explain to Parkinson's disease patients and caregivers the freezing of gait symptom (Freezing of gait is an abnormal gait pattern that } \\
\text { can accompany Parkinson's disease (PD) as well as other parkinsonian disorders in which there are sudden, short and temporary } \\
\text { episodes of an inability to move the feet forward despite the intention to walk) and implements ways of reducing its effect [8]. }\end{array}$ \\
\hline Ideal Goal & $\begin{array}{l}\text { Develop a Biomechatronics devices that will help to detect and handle the freezing of gait in Parkinson's patients to avoid frequently } \\
\text { falls [7]. }\end{array}$ \\
\hline $\begin{array}{l}\text { Current } \\
\text { advances }\end{array}$ & $\begin{array}{l}\text { Christopher Bishop, PhD, at Binghamton University in Binghamton, NY, is studying an area of the brainstem known as the } \\
\text { pedunculopontine nucleus, which plays a key role in movement and wakefulness. It has been an experimental DBS target for relief of } \\
\text { freezing of gait and PD-related gait disorders with mixed results. Dr. Bishop is probing the specific functions of this key brain area to } \\
\text { determine how they impact PD symptoms [8]. Portable Biomechatronics device with external sensory cues to diminish freeze of gait } \\
\text { in Parkinson's disease (see Section 7.6.7.3 [7]) }\end{array}$ \\
\hline Section: & Standing Still Without Falling \\
\hline $\begin{array}{l}\text { Patient side } \\
\text { view }\end{array}$ & He discovers that at some point he couldn't stand right either, and related it with proprioception failure. \\
\hline $\begin{array}{l}\text { Research side } \\
\text { view }\end{array}$ & $\begin{array}{l}\text { Parkinson's affects control of automatic activities, so posture changes may occur without the brain's automatic reminders to stand up } \\
\text { straight. These changes may include stooped or rounded shoulders, decreased low back curve or forward lean of the head or whole } \\
\text { body, making you look hunched over [9] }\end{array}$ \\
\hline Ideal Goal & $\begin{array}{l}\text { It is important to try to maintain an upright posture because stooped posture can have other negative effects as neck or back pain, } \\
\text { ability to take beep breaths, loss of flexibility, lead to off balance and lead to falls. }\end{array}$ \\
\hline $\begin{array}{c}\text { Current } \\
\text { advances }\end{array}$ & Some of them are: Posture exercises [10]. Yoga or Tai Chi classes \\
\hline
\end{tabular}

\begin{tabular}{|c|c|c|}
\hline Section: & My Hand Forgets How to Brush My Teeth \\
\hline $\begin{array}{c}\text { Patient side } \\
\text { view }\end{array}$ & $\begin{array}{c}\text { He discovers by himself that at some point that the motor control sequence in his brain for brushing teeth was no longer functioning. } \\
\text { Finally, he decides to use an electric toothbrush. }\end{array}$ \\
\hline $\begin{array}{c}\text { Research side } \\
\text { view }\end{array}$ & $\begin{array}{c}\text { The lack of fine motor control causes dexterity issues and co-ordination problems are frequently symptom of Parkinson' disease. } \\
\text { As the changes are gradual, patients may not realize or be in denial that they are no longer able to carry out certain activities safely } \\
\text { [11]. Apraxia is the difficult to perform or carrying out an action, for example like brushing teeth. There are a variety of treatments } \\
\text { that can help manage the motor symptoms and improve the quality of life, but there is no known treatment to stop or slow the } \\
\text { disease progression that is different in each patient. The current treatments available must be prescribed by a neurologist, these are: } \\
\text { medications, surgical treatments and complementary/alternative therapies [1]. }\end{array}$ \\
\hline Ideal Goal & $\begin{array}{c}\text { Find a way to stop or slow the Parkinson's disease. } \\
\text { Current } \\
\text { advances }\end{array}$ & $\begin{array}{c}\text { The currently used drugs for treatment of Parkinson's disease are only symptomatic of these diseases, but do not stop the process } \\
\text { of neuron loss. Possibly, a better understanding on the molecular mechanisms of these neurodegenerative diseases will help us to } \\
\text { get effective drugs for treatment of these diseases in future. Thus, the strategy for development of potential neuroprotective drugs } \\
\text { for amelioration of the symptoms of the diseases, improvement of neuronal cells loss and restoration of normal brain functioning in } \\
\text { both Parkinson's disease patients, is a great challenge for basic science and clinical medicine [12]. NMDA receptor antagonist (it is } \\
\text { a class of anesthetics that work to antagonize, or inhibit the action of receptor), could be a potential target for treatment of non- } \\
\text { motor symptoms, such as cognitive dysfunction, depression and anxiety of PD patients [13]. Blockers of calcium channels could be a } \\
\text { prospective molecular target for treatment of PD [14]. }\end{array}$ \\
\hline
\end{tabular}

\begin{tabular}{|c|c|}
\hline Section: & Not Yet Parkinson's \\
\hline Patient side view & $\begin{array}{c}\text { The patient got frustrated when a doctor mentioned him as a comment as an experience feeling that he probably will develop } \\
\text { Parkinson's disease in the next } 10 \text { years. }\end{array}$ \\
\hline Research side view & $\begin{array}{l}\text { Progressive Neurodegenerative disease as Parkinson's are very hard to diagnose even for a neurologist after analyzing all } \\
\text { medical historical: lab tests, brain MRI, and study of nerve conduction. Therefore, until now they take years to diagnose } \\
\text { Parkinson's disease. }\end{array}$ \\
\hline
\end{tabular}




\begin{tabular}{|c|c|c|}
\hline Ideal Goal & $\begin{array}{c}\text { Find marker for Parkinson's disease. Parkinson's disease (PD) is known to have a long prodromal stage due to the degeneration } \\
\text { of dopaminergic neurons of the substantia nigra pars compacta over the course of many years without clinical manifestations } \\
\text { of PD. When the diagnosis is made, the neuropathological process is already well entrenched. Consequently, identifying } \\
\text { individuals during this prodromal period could be very helpful for future trials of neuroprotective or disease-modifying } \\
\text { therapies, which might slow or prevent the degeneration of dopaminergic neurons. Thus, efforts are needed to determine } \\
\text { appropriate early markers of PD [15] [16]. }\end{array}$ \\
\hline Current advances & $\begin{array}{c}\text { Some of them are: } \\
\text { Measures of gait and balance could be early markers of preclinical PD. Further studies are needed to identify more specific and } \\
\text { more sensitive markers to detect individuals at-risk of developing idiopathic PD [7,15]. Preclinical markers are on evaluation: } \\
\text { LRRK2 gene mutation and PINK1 gene mutation. Special methodologies that relate and measure: limbs angles in 3D with } \\
\text { muscles involved activities during gait cycles, as explain in my book/ebook: Applied Biomechatronics Using Mathematical } \\
\text { Models [7]. }\end{array}$ \\
\hline
\end{tabular}

\section{Parkinson's Disease General Acknowledges (by Jorge Garza-Ulloa)}

It is very import to remain that symptoms are different for each patient in intensity, duration and combination of them. Only your doctor trained in nervous system conditions (neurologist) can diagnose Parkinson's disease. He will decide, if your symptoms are from Parkinson disease, specify Parkinson's disease stage, and the Parkinson disease type. The diagnose will take time and it must be based facts on your medical history (lab tests results, MRI's), review of your signs and symptoms, and a neurological and physical examination.

As a patient and caregiver, it is very important to have a general acknowledge of Parkinson's disease: on frequently symptoms, disease stages and Parkinson's disease types. These are explained in the next three sections:

\section{Parkinson's disease symptoms}

The most main symptoms are of three kinds: primary motors (directly related to movement), secondary motors (consequence of movement disorders) and non-motors (no related to movement disorders) [1].

1. Motors (directly related to movement) as: Tremors in limbs, Rigidity (muscle stiffness), Bradykinesia (slowness of movements), and Postural instability (impaired balance or difficulty standing or walking.

2. Secondary motor (consequence of movement disorders) as: loss of facial expressions, temporary gait hesitation or dragging of the feet, unwanted accelerations when walking, speech difficulty or changes in speech, stooped posture, prolonged muscle contractions, impaired fine motor dexterity, poverty of movement, restless movements, difficulty swallowing, muscles may stay in a contracted position and cause pain, sexual dysfunction, muscle weakness, and others.

3. Non-motors (no related to movement disorders) as: fatigue, digestive issues, urinary problems, sleep problems, low blood pressure that occurs when rising to a standing position, increased sweating, increased drooling, pain, muscle rigidity, reduced sense of smell, mood changes, psychotic symptoms (hallucinations, paranoia, and agitation), cognitive changes including memory difficulties, slowed thinking, confusion, impaired visual-spatial skills (such as getting lost in familiar locations), dementia and others.

\section{Parkinson's disease stages}

To understand the state of this disease, we have to know the Parkinson's disease stages, these are typical patterns of progression in Parkinson's disease that are defined in five stages [2], These are: 1) Mild symptoms (Do not interfere with daily activities), 2) Getting worse (Difficult and lengthy in daily activities), 3) Mid-stage (Impair in daily activities such as dressing and eating), 4) Severe and Limiting (Person needs help with activities of daily activities) and 5) Most advanced and debilitating stage (person requires a wheelchair or is bedridden. Around-the-clock nursing care is required for all activities). The main problem is that not everyone will experience all the symptoms of Parkinson's, and if they do, they won't necessarily experience them in quite the same order or at the same intensity, this is why the actual stage(s) and the evolution must be deducted only for the neurologist.

\section{Parkinson's disease types}

Parkinsonism is a constellation of signs and symptoms that are characteristically observed in Parkinson's disease (PD), but that are not necessarily due to PD. Parkinsonism is the primary type of hypokinetic movement disorder. Parkinsonism describe the collection of signs and symptoms found in Parkinson's disease (PD).

Parkinson's disease types, these are two general types [3]:

1. Idiopathic Parkinson's (Tremor predominant disorder that involves shaking and trembling, affect about $85 \%$ of Parkinson's patients), and

2. Atypical Parkinsonism (Instability and gait disorder that present more trouble with walking and balance, affect about $15 \%$ of Parkinson's patients). Atypical parkinsonism is less common, it is an instability and gait disorder that present more trouble with walking and balance, these are rarer conditions and more difficult to treat. This type of Parkinson's disease happens at an older age but tends to progress quickly. Although people may experience fewer tremors or no tremors at all, they have a higher risk of cognitive decline. Atypical parkinsonism includes the following variations: Multiple System Atrophy, 
Progressive Supranuclear Palsy, Corticobasal Syndrome, Dementia with Lewy bodies, Drug-induced Parkinsonism, and Vascular Parkinsonism.

In this case, the patient was confirmed by his neurologist: Atypical Parkinsonism of subtype: Multiple System Atrophy (MSA), these types include several neurodegenerative disorders in which one or more systems in the body deteriorates as: incoordination (ataxia), dysfunction in the autonomic nervous system that automatically controls things such as blood pressure and bladder function. These are in addition to variable degrees of parkinsonism including symptoms such as slowness, stiffness and imbalance.

\section{Conclusions (by Jorge Garza-Ulloa)}

Parkinson's disease (PD) is a progressive nervous system disorder that affect movement and present symptoms, that can be different for everyone and the exact cause of this damage is still unknown [1]. All medication and procedures available today only help to improve the quality of life of the patients. There is a big necessity to focus in more ways to accelerate the research for stop the evolution of Parkinson's disease, and if it is possible find a way to slow down, stop or cure in a near future. Some ideal way on my opinion could be:

The creation of a cloud database with information and feedback from: patients, caregivers, researches, radiologists, doctors and other persons involved in the disease. With the goal to develop mathematical models using Artificial intelligence that allow analyze, classify, and forecast progression, that can be useful to measure and track the disease, allowing an evaluation on new medicines, new surgeries and new methods. These will help in the definition of new criteria's involving multidiscipline research to analyze the disease form combined perspectives, and find ways for early detection, stop the disease progression and many other goals.

it is very Important to access more information of degenerative neurological disease, that could help to understand the diseases from the patient's point of view. If you have more cases/information about the evolution of Parkinson's disease or any other neurologic disease in patients please send them to the email: HYPERLINK"mailto:jorge@ garzaulloa.org" jorge@garzaulloa.org.We will collect them, analyze, classify, publish and share all the information to everyone interested.

\section{References}

1. Jorge Garza-Ulloa (2019) Update on Parkinson's Disease. Am J Biomed Sci \& Res 2(6): 229236.

2. (2019) Stages of Parkinson's.

3. Ryan Barmore (2019) Types of Parkinsonism. Parkinson's Foundation

4. https://www.mayoclinic.org/diseases-conditions/parkinsons-disease/ diagnosis-treatment/drc-20376062.

5. Kai C Sonntag, Bin Song, Nayeon Lee, Schweitzer J, Kim KS, et al. (2018) Pluripotent stem cell-based therapy for Parkinson's disease: Current status and future prospects. Progress in Neurobiology 168: 1-20.

6. Shreya Bhat, U Rajendra Acharya, Dadmehr N, Adeli H, Hagiwara Y (2018) Parkinson's disease: Cause factors, measurable indicators, and early diagnosis, Computers in Biology and Medicine 102(1): 234-241.

7. Jorge Garza Ulloa (2018) Applied bio mechatronics Using Mathematical Models. $1^{\text {st }}$ Edn Elsevier-Academic Press.

8. Rebecca Gilbert (2019) Freezing of Gait in Parkinson's disease.

9. Bradykinesia (Slowness of Movement).

10. https://f5h3y5n7.stackpathcdn.com/sites/default/files/attachments/ Posture_and_Parkinsons.pdf

11. http://www.parkinsonsdiseaseearlysymptoms.com/tag/fine-motor-control

12. Biswanath Dinda, Manikarna Dinda, Goutam Kulsi, Ankita Chakraborty, Subhajit Dinda (2019) Therapeutic potentials of plant iridoids in Alzheimer's and Parkinson's diseases: A review. Eur J Med Chem 69(1): 185199.

13. C Ji A, Xue GF, Lijun C, Feng P, Li D, et al. (2016) Novel dual GLP-1 and GLP receptor agonist is neuroprotective in the MPTP mouse model of Parkinson's disease by increasing the expression of BDNF. Brain Res 1634 1-11.

14. https://www.annualreviews.org/doi/abs/10.1146/annurev-pharmtox-010818-021214

15. Nathalie Chastan, Leslie M (2019) Decker, Posturo-locomotor markers of preclinical Parkinson's disease, Neurophysiologie Clinique 49(2): 173-180.

16. Jorge Garza-Ulloa, Project for new book and new research papers "Applied Biomedical Engineering Using Artificial Intelligence And Cognitive Models “, 